\title{
Participation of Cultured Mesenchymal Multipotent Stromal Cells in Regeneration of a Large Persisting Defect of Rabbit Radius Bone
}

\author{
Mamonov V.E., Shipounova I.N., Sats N.V., Bigildeev A.E., Svinareva D.A., Proskurina N.V., \\ Riashentsev M.M., Chemis A.G. and Drize N.I.
}

National Haematology Research Centre, Nov. Zykovsky pr. 4, Moscow, 125167, Russia

\begin{abstract}
The aim of this work was to characterize the impact of autologous cultured mesenchymal multipotent stromal cells (MMSCs) on the repair of large persisting defect in rabbit radius bone. MMSCs were obtained from femoral bone marrow aspirate, cultivated during 2-3 passages and marked by lentiviral vectors containing genes encoding green or cherry fluorescent proteins 4-6 days before implantation. The implantation of MMSCs resulted in new bone formation within 12 weeks. Cultured MMSC differentiated into bone, cartilage and other connective tissues in vivo. Mineral matrix used as a carrier of MMSC was completely resorbed in 10 weeks. Implanted MMSCs bearing marking gene maintained newly formed bone and cartilage tissues for at least one year. Thus, cultured MMSCs preserve the ability to differentiate and maintain bone tissue for long-term period in vivo, suggesting their high proliferative potential. Therefore, they could be used in tissue engineering in the healing of large bone defects.
\end{abstract}

Keywords: Bone defect, lentiviral vector, multipotent mesenchymal stromal cells.

\section{INTRODUCTION}

The development of new trends such as cytotherapy and tissue engineering in the therapy of various diseases was partly brought about by the advanced knowledge of mesenchymal stem cells and their properties [1,2]. Described more than 40 years ago by A. Friedenstein [3] as stromal mechanocytes and named 20 years ago by A. Caplan [4], mesenchymal stem cells (MSC) are now one of the most important cell technologies. To have the "stem cell" label, MSCs have to meet generally accepted criteria: ability to self-renew and differentiate into any mesenchymal cell type. For murine MSC the ability to differentiate [5] and selfrenew [6] has been clearly proven. For human cells, it was suggested that MSCs be defined as fibroblast-like, plasticadherent cells from bone marrow able to differentiate into bone, cartilage and adipocytes under the influence of appropriate induction in vitro [4]. For such cells, it is impossible to prove the ability to self-renew; thus, the International Society for Cellular Therapy suggests that these cells be termed multipotent mesenchymal stromal cells (MMSC) [7], whereas the term MSC should be used only for cells that meet specified stem cell criteria. In cell therapy and regenerative medicine, mesenchymal precursor cells analogous to MMSC are used. Transplantation of MMSCs to humans with subsequent regeneration of damaged tissues is widely used; however, the role of MMSCs in this process is often obscure: does their trophic function or the ability to differentiate into specific tissue lead to positive results? The longevity of functioning of transplanted MMSCs is not known $[8,9]$. MMSCs are also used for healing the defects of the supporting-motor system. Different proposals for

*Address correspondence to this author at the Nov. Zykovsky pr. 4, Moscow, 125167, Russia; Tel: +7 (495) 612 3521; Fax: +7 (495) 612 3521; E-mail:ndrize@yandex.ru healing osteochondral tissues, including perichondral and periosteal remodelling as well as transplantation of chondrocytes and MMSCs have been suggested [10-12]. However, none of the methods used gave stable reproducible results. The tissue regeneration was maintained for a limited time and long-term observation revealed degenerative changes [13]. Thus, the question about the functioning of cultured MMSCs in vivo and their or their progeny's, participation in tissue regeneration is important. In the haematopoietic system, induction of differentiation leads to decreased proliferative potential, and the duration of committed precursor cell function is short. The MSC compartment also possesses a hierarchical structure [14]. However, it is not known if the induction of MMSCs to differentiation in vitro influences the longevity of their functioning in vivo.

Several animal models exist for investigation of regenerative potential of MMSCs. The use of murine and rat models for study the regeneration of bone and cartilage tissues is difficult because the growth characteristics of their MMSCs in vitro differ significantly from those of human [15]. Rabbit and sheep MMSCs most adequately reproduce the features of human cells $[16,17]$.

The aim of the study was to investigate the ability of rabbit MMSCs to repair a critical bone defect in a long bone shaft over time. The participation of cultured MMSC in new bone formation was to be proven by the detection of marked by lentiviral vector MMSCs or their progeny. The data obtained provide strong evidence that MMSCs implanted into the site of the defect take part in the healing of bone, cartilage and connective tissues. MMSCs and/or their progeny are detected in repaired tissues throughout one year. Therefore, cultured MMSCs possess high proliferative potential and the ability to differentiate into different mesenchymal lines in vivo. 


\section{METHODS}

\section{Experimental Design}

Shortly, experiments were designed as follows: bone marrow was aspirated and MMSCs cultures were established and cultured for 2-3 passages to obtain confluent monolayer in 10 T175 culture flasks. One out of 10 flasks was infected with lentiviral vector, containing gene coding fluorescent green or red proteins. In order to investigate the importance of intercellular contacts in MMSC population cells were implanted on Indost sponge either as suspension or as scrapped monolayer. The necessity of previous induction of osteogenic differentiation was studied by implanting undifferentiated MMSCs, MMSCs induced to ostegenesis for 4 days in culture and combination of induced and undifferentiated MMSCs in equal parts. In total 6 experimental groups were studied: 1). MMSCs as suspension; 2). MMSCs as monolayer; 3). MMSCs osteo (induced to osteogenic differentiation) as suspension; 4). MMSCs osteo as monolayer; 5). combination of induced and undifferentiated MMSCs as suspension ; 6). combination of induced and undifferentiated MMSCs as monolayers. For each experimental group 3 animals were used. Sponge with all cells and ProDense granules were implanted to the region of critical defect of rabbit radius bone (Fig. 1). The dynamics of defect repair was analysed by radiography every 3 months starting from one week after operation.

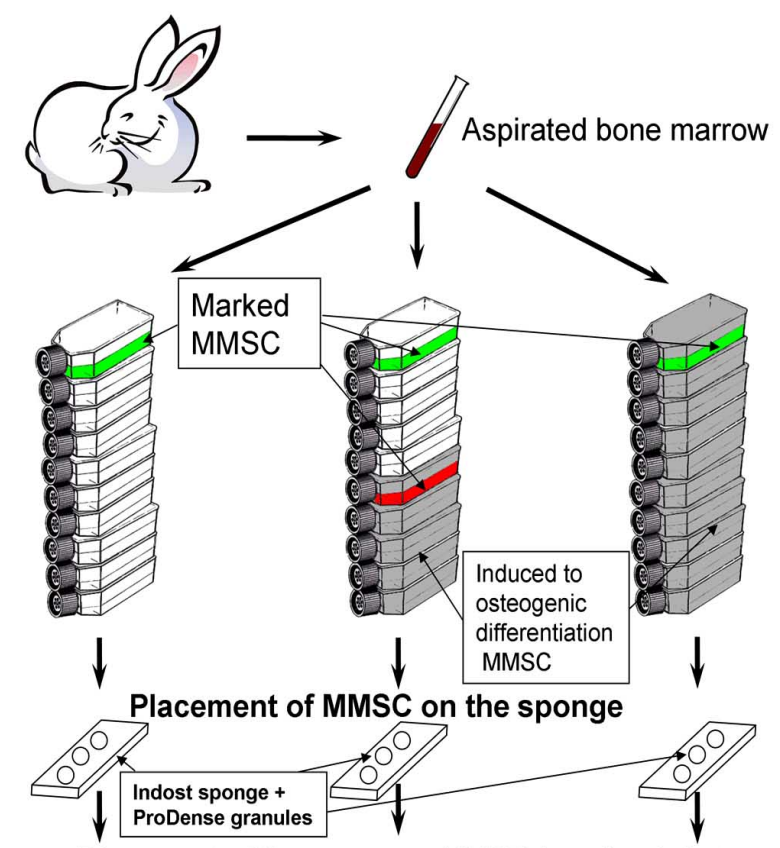

Placement of the sponge + MMSC into the defect
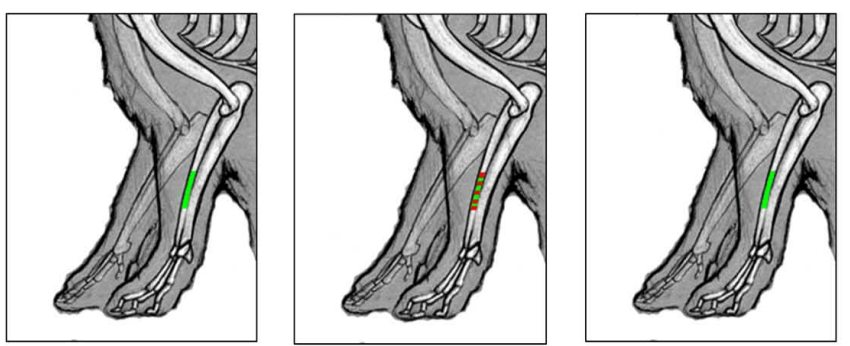

Fig. (1). Experimental design.

\section{Materials}

Adult "Sovetskaya shinshilla" rabbits at the age of 10-12 months at the beginning of the experiments were used. Male and female animals from the filial "Beliy Moch" from the Scientific Centre for Biomedical Science, Russian Academy of Medical Science were housed in individual cages and provided with standard mixed fodder and rich fodder. Animal care and experimental procedures were performed under approval from the Animal Care Committee of the Institute of Medico-Biological Problems Russian Academy of Science, protocol number 257.

For MMSCs, a portion of femoral bone marrow was aspirated into tubes with $500 \mathrm{U} / \mathrm{ml}$ of heparin under infiltrating anaesthesia. A $15-20 \mathrm{ml}$ volume of $0.5 \%$ Novocaine (public corporation "Organica", Russia) was injected subcutaneously, intramuscular and under periosteum.

For mononuclear cells, the bone marrow was mixed with an equal volume of alfa-MEM (ICN) media containing $0.2 \%$ methylcellulose (1500 cP, Sigma-Aldrich). In $40 \mathrm{~min}$, most erythrocytes and granulocytes had precipitated, while mononuclear cells remained in suspension. Suspension (upper) fraction was aspirated and centrifuged for 5 minutes and $1500 \mathrm{rpm}$.

Cells in the suspension fraction were washed with phosphate buffer saline (PBS, ICN), centrifuged as mentioned above and resuspended in standard cultivation medium combined from alfa-MEM supplemented with $10 \%$ foetal calf serum (FCS, Hyclone), 2 mM L-glutamine (ICN), 100 $\mathrm{U} / \mathrm{ml}$ penicillin (Ferein) and $50 \mu \mathrm{g} / \mathrm{ml}$ streptomycin (Ferein), and $3 \times 10^{6}$ cells were cultured in T25 culture flasks. When a confluent monolayer had formed, cells were washed with $0.02 \%$ EDTA (ICN) in physiologic solution (Sigma-Aldrich) and then trypsinized (ICN). From that point all cells were grown in T175 culture flasks. Cells were seeded as $4 \times 10^{3}$ cells per $\mathrm{cm}^{2}$ of flask area.

The population-doubling level (PDL) was measured using the following formula:

$$
\mathrm{PDL}=3.32 *\left(\log \mathrm{N}_{\mathrm{H}}-\log \mathrm{N}_{\mathrm{S}}\right),
$$

where $\mathrm{N}_{\mathrm{H}}$ is the number of harvested cells at the end of the growth period, and $\mathrm{N}_{\mathrm{S}}$ the number of seeded cells [18].

\section{Induction of Differentiation}

For in vitro differentiation into osteoblasts or adipocytes cells were induced with osteogenic induction medium, composed of standard cultivation medium described above with $0.1 \mathrm{mkM}$ dexamethasone, $0.15 \mathrm{mM}$ ascorbate-2-phosphate and $3 \mathrm{mM} \mathrm{NaH} \mathrm{PO}_{4}$ (all Sigma-Aldrich); or adipogenic induction medium, composed of standard cultivation medium with $1 \mathrm{mkM}$ dexamethasone , $60 \mathrm{mkM}$ indomethacin, 5 $\mathrm{mkg} / \mathrm{ml}$ insulin (all Sigma-Aldrich). After the appearance of morphologic features of differentiation (2 weeks usually) cells were stained with Alizarin red S and Oil Red O (both Sigma-Aldrich), respectively. Cells meant for the staining were initially plated on the sterile cover glasses put in 6-well plates and cultivated as described before. Alizarin red $\mathrm{S}$ staining was performed as follows: cells were washed with PBS, fixed in 10\% neutral buffered formalin or alcoholic formalin for 10 minutes, and then washed with PBS again. After that a drop of Alisarin Red S solution ( $2 \%$ by weight in 
water, $\mathrm{pH} 4.1-4.3$ adjusted by $10 \% \mathrm{NH}_{4} \mathrm{Cl}$ (Sigma-Aldrich)) was overlaid onto each cover glass and incubated for 5 minutes. Then the staining solution was blotted and cells were dehydrated in acetone (Himmed, Russia) (20 dips), in acetone-xylene (1:1) solution (20 dips), in xylene (Himmed, Russia) (20 dips) and mounted in a Canada balsam (DC Pancreac). Oil Red $\mathrm{O}$ staining was performed as follows: cells were washed with PBS, then a drop of Oil Red O working solution $(30 \mathrm{ml}$ of stock solution $(0.5 \%$ in isopropanol) mixed with $20 \mathrm{ml}$ of distilled water, left for 10 minutes, then filtered through filter paper) was overlaid onto each cover glass and incubated for 10-12 minutes. Then briefly (for 20 seconds) rinsed in distilled water and after that incubate for 10 minutes in flowing water. Then the glasses were dried with filtered paper and mounted in Mowiol $^{\circledR}$ 4-88 G2 (Eurohim, Russia).

Osteogenic differentiation of MMSC (osteo-MMSC) meant for implantation was induced in vitro for 4 days before the operation. Such short time for induction of osteogenic differentiation was chosen in order to shift slightly some MMSC toward osteogenic lineage but avoid terminal differentiation. Mature cells in bone tissue are not able to self-renew and as a result not suitable for defect regeneration and long-term maintenance of bone tissue.

\section{Marking of MMSC}

Third generation lentivectors (SIN) HIV LeGO encoding EGFP and mCherry were produced by means of plasmids phCMVC-VSV-G (R861), pGpur(R1246), pMDLg/pRRE and pRSV Rev, kindly provided by Kristoffer Weber, Prof. Boris Fehse (University Hospital Eppendorf, Hamburg), Dr.
Carol Stocking (Heinrich-Pette-Institute, Hamburg) and Roger Y. Tsien (Howard Hughes Medical Institute Laboratories at the University of California, San Diego).

For viral transduction, $300 \mu 1$ of concentrated viral particles $\left(10^{8}\right.$ viral particles $\left./ \mathrm{ml}\right)$ in $9 \mathrm{ml}$ of alfa-MEM with $10 \%$ FCS and $8 \mu \mathrm{g} / \mathrm{ml}$ polybrene (Sigma-Aldrich) per T175 flask were overlaid on the MMSC monolayer for 6 hours, then the media was replaced with $25 \mathrm{ml}$ of fresh standard cultivation medium. The efficiency of infection was estimated under fluorescent microscope prior to implantation.

\section{Operation}

MMSCs from 10 T175 flasks for each transplantation were detached either by trypsinisation or with the help of a scraper, centrifuged (10 min, $1000 \mathrm{rpm}$ ) for pellet formation and placed on macroporous bioceramic sponge Indost (collagen with hydroxyapatite, Polystom, Russia) in order to avoid their crawling away. Cylindrical chips of ProDense (calcium sulphate with calcium phosphate biomaterial, WMT, USA) sized $3 \times 3 \mathrm{~mm}$ and more than $10 \mathrm{MPa}$ density were formed prior to animal manipulation and used as suitable scaffold for tissue engineering.

The stages of bone defect formation and MMSC insertion are shown in Fig. (2).

Forelimb was washed with $10 \%$ solution of Iodopiron (public corporation Troizkiy Iodniy Zavod, Russia) or Akvazan ("Iodnie Technologii I Marketing", Russia) aseptically. Infiltration of forearm fascial compartments was performed using a $0.5 \%$ solution of Novocain, which guaranteed anaesthesia for the duration of the operation.
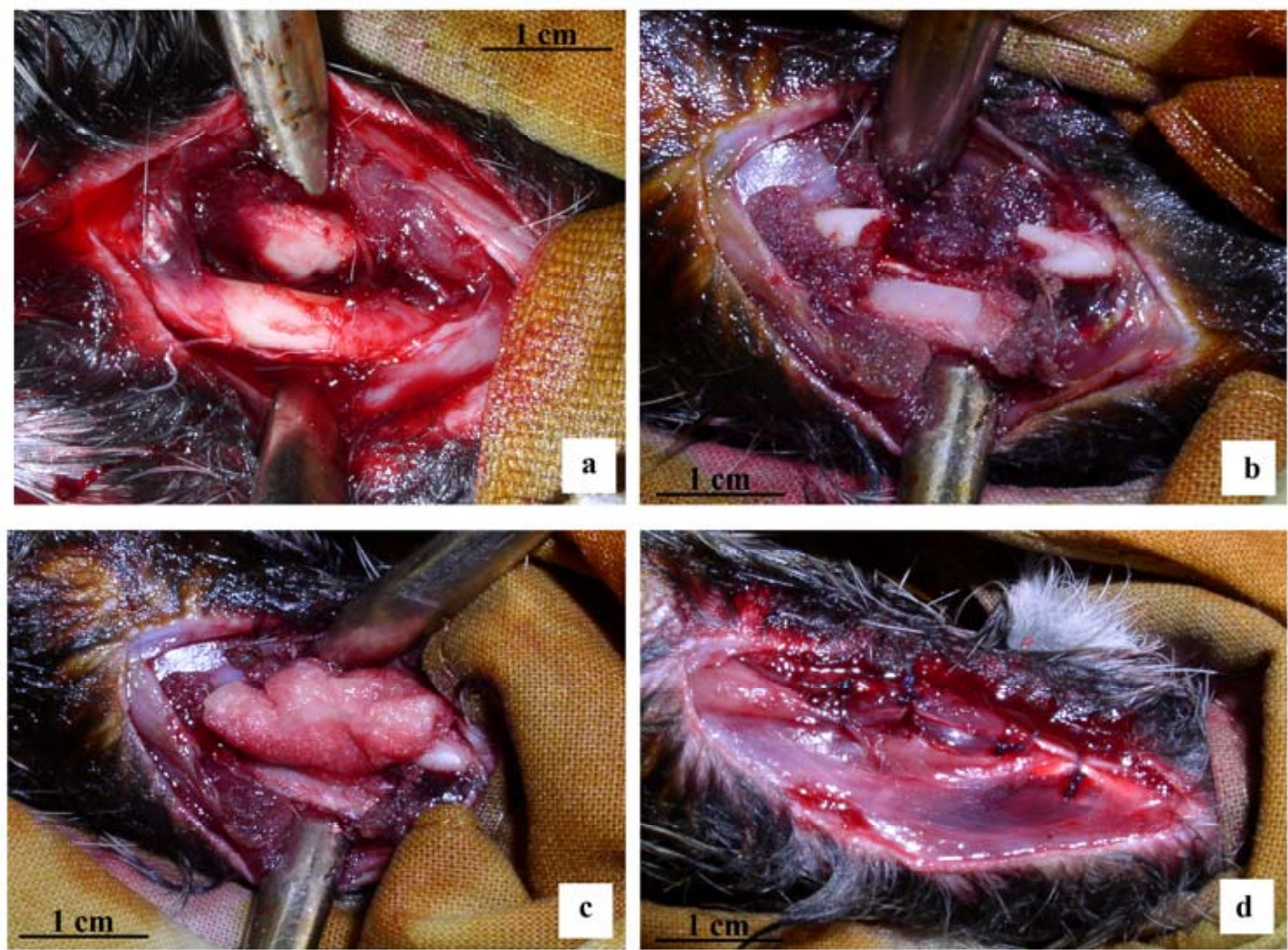

Fig. (2). Stages of operation. a. Assessment of intact radius bone; b. Dissection of $10 \mathrm{~mm}$ of radius bone fragment; c. Implantation of MMSCs on Indost sponge. ProDense cylinders were placed into the defect and covered with the sponge; d. Muscle fascia closure. 


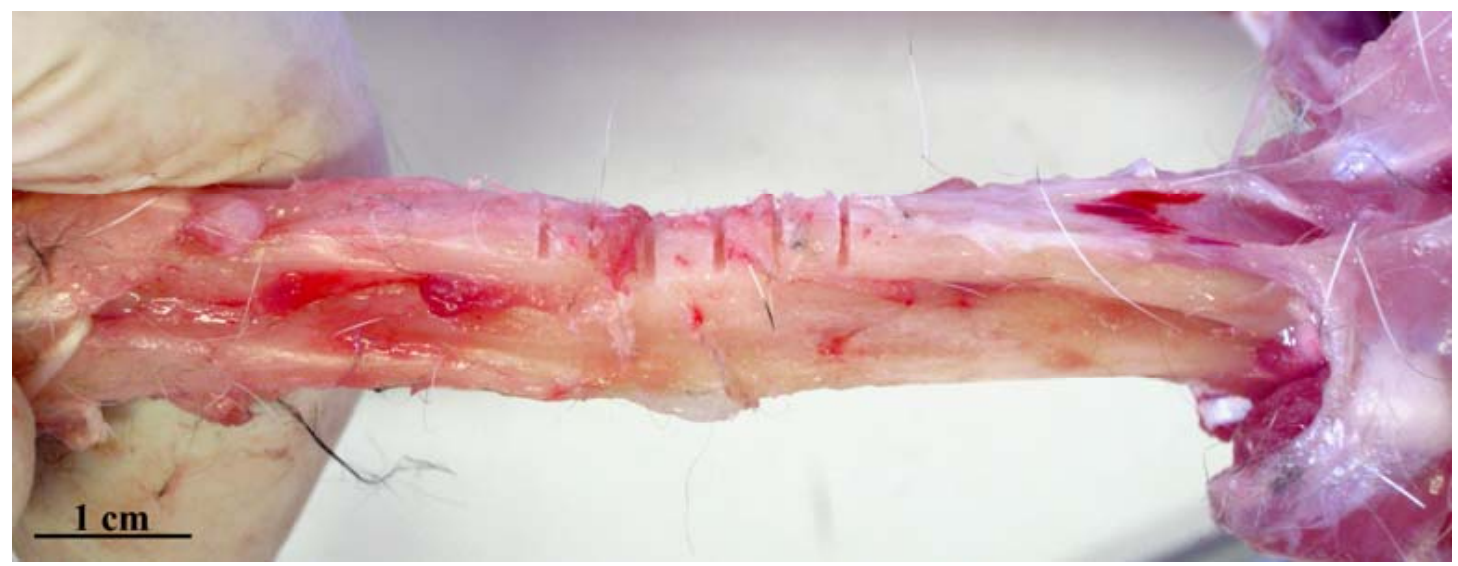

Fig. (3). Marking of the newly formed bone tissue for DNA isolation.

Access to radial shaft was gained through a $30-35 \mathrm{~mm}$ longitudinal section in the middle third of the forearm. The resection zone was freed from the periosteum. The 10-13 $\mathrm{mm}$ resection was performed by oscillated saw. The formed defect was filled with 3 - 6 cylinders of ProDense (WMT, USA) and Indost sponge (Polystom, Russia) with autologous MMSCs, according to the experimental design. Superficial fascia and skin with subcutaneous cellular tissue were closed separately. The forearm was fixed by dorsal cast from the nail tips to the upper third of the humerus in a position of $90^{\circ}$ flexion in the elbow.

For five days after the operation, the rabbits were treated subcutaneously with a 5\% solution of Enterocept (Vetbiochim, Russia), the final dosage was $0.1 \mathrm{ml}$ per kilogram.

The progress of defect healing was analysed periodically by X-ray study. The results were compared with X-ray pictures taken one week after operation.

The defect in control animals was either not filled, or was filled with Indost sponge and ProDense cylinders without MMSCs. The wound was closed tightly layer by layer as stated above. For analysis of the origin of the cells in newly formed bone tissue 3-5 pieces were dissected from each bone (Fig. 3). Newly formed cartilage and connective tissue were dissected separately.

\section{Analysis of Tissue Regenerates}

DNA was extracted from all tissue samples by following method. Bone sections were frozen in liquid nitrogen, pounded in a few drops of lysis solution $(50 \mathrm{mM}$ Tris- $\mathrm{HCl}$, $\mathrm{pH}$ 8.0, 2\% SDS Na, 2mM EDTA, pH 8.0, all Sigma), then each probe was transferred in $1.25 \mathrm{ml}$ of lysis solution with 5 $\mathrm{mkl}$ of proteinase $\mathrm{K}$ (Fermentas) and incubated with constant swinging in $55^{\circ} \mathrm{C}$ overnight. Then probes were cooled and mixed with equal volume of neutralized phenol and centrifuged for 10 minutes with $10000 \mathrm{rpm}$. After that aqueous phase of each probe was transferred into new tubes, mixed with equal volume of chlorophorm: isoamyl alcohol (24:1) mixture, centrifuged for 10 minutes with $10000 \mathrm{rpm}$, then aqueous phase of each probe was transferred into new tubes, mixed with $5 \mathrm{M} \mathrm{NaCl}$ (Sigma) (1/50 of the volume of aqueous phase) and $96^{\circ}$ ethanol (2.5 volumes of aqueous phase). The probes were incubated overnight in $-20^{\circ} \mathrm{C}$, then centrifuged for 10 minutes with $10000 \mathrm{rpm}$, washed with 1 $\mathrm{ml}$ of $70^{\circ}$ ethanol, centrifuged for 10 minutes with 10000 rpm, after that the pellets were air dried and dissolved in 100 mkl of Tris EDTA (TE) solution.

For detection of the marked cells from bone, cartilage and connective tissues, PCR analysis was applied for 11 animals. For EGFP detection, the following primers were used: EGFP-w1: 5'-ATGGTGAGCAAGGGCGAGGA-3' (forward) and EGFP-C1: 5'-AGACGTTGTGGCTGTTGTA G-3' (reverse) (454 bp fragment); and for mCherry (C2), ChD: 5'-ACCCAGGACTCCTCCCTG-CA -3' (forward) and Ch-com-R : 5'-CACATAGCGTAAAAGGAGCAAC -3' (reverse), (559 bp fragment). PCR was performed using 3236 cycles under the following conditions: $94^{\circ} \mathrm{C}-1 \mathrm{~min}$, $62^{\circ} \mathrm{C}-1 \mathrm{~min}, 72^{\circ} \mathrm{C}-2 \mathrm{~min}$. PCR mixture ( $20 \mathrm{mkl}$ ) contained $2 \mathrm{mM} \quad \mathrm{MgCl} 2$ (Fermentas), $0.25 \mathrm{mM}$ dNTP (Promega), $0.17 \mathrm{mg} / \mathrm{ml}$ bovine serum albumin (Sigma), $1 \mathrm{M}$ betaine (BioUltra, Sigma), 5\% DMSO (AppliChem GmbH), $0.5 \mathrm{pM} / \mathrm{mkl}$ of each primer, 1U/probe of Taq Polymerase (Fermentas) and corresponding volume of PCR buffer (Fermentas). The amplification products were separated on $1.5 \%$ agarose gel in Tris acetate EDTA (TAE) buffer. In all PCRs no template controls were analyzed to exclude DNA contamination.

For histological analysis saw cuts of newly formed bone tissues were fixed in Bowen solution $(15 \mathrm{ml}$ of saturated solution of picric acid, $5 \mathrm{ml}$ of neutralized formalin and $1 \mathrm{ml}$ of glacial acetic acid (added just before use)), decalcified in $5 \%$ nitric acid (Himmed, Russia) for 8-10 hours followed by $24 \mathrm{~h}$ incubation in $5 \%$ sodium sulphate (Himmed, Russia). Then the samples were washed in running water for 1-2 days and then routine paraffin embedding was performed. The samples were cut on microtome and 5 -mkm slides were stained with haematoxylin-eosin or Mallory staining. Haematoxylin-eosin staining was performed as follows: sections were deparaffinized and incubated with haematoxylin (Merk, Germany) for $10 \mathrm{~min}$, then washed with tap water until the nuclei became blue and incubated with eosin (Merk, Germany) for a few seconds. After that slides were washed in distilled water, dehydrated and mounted in Canada balsam. For Mallory staining sections were deparaffinized and incubated in $0.1 \%$ acid fuchsin (Merk, Germany) for 3 min, washed in distilled water, incubated in $1 \%$ phosphotungstic acid (Himmed, Russia) for 5 minutes, washed in distilled water, stained with Mallory stain $(0.5 \mathrm{~g}$ of aniline 

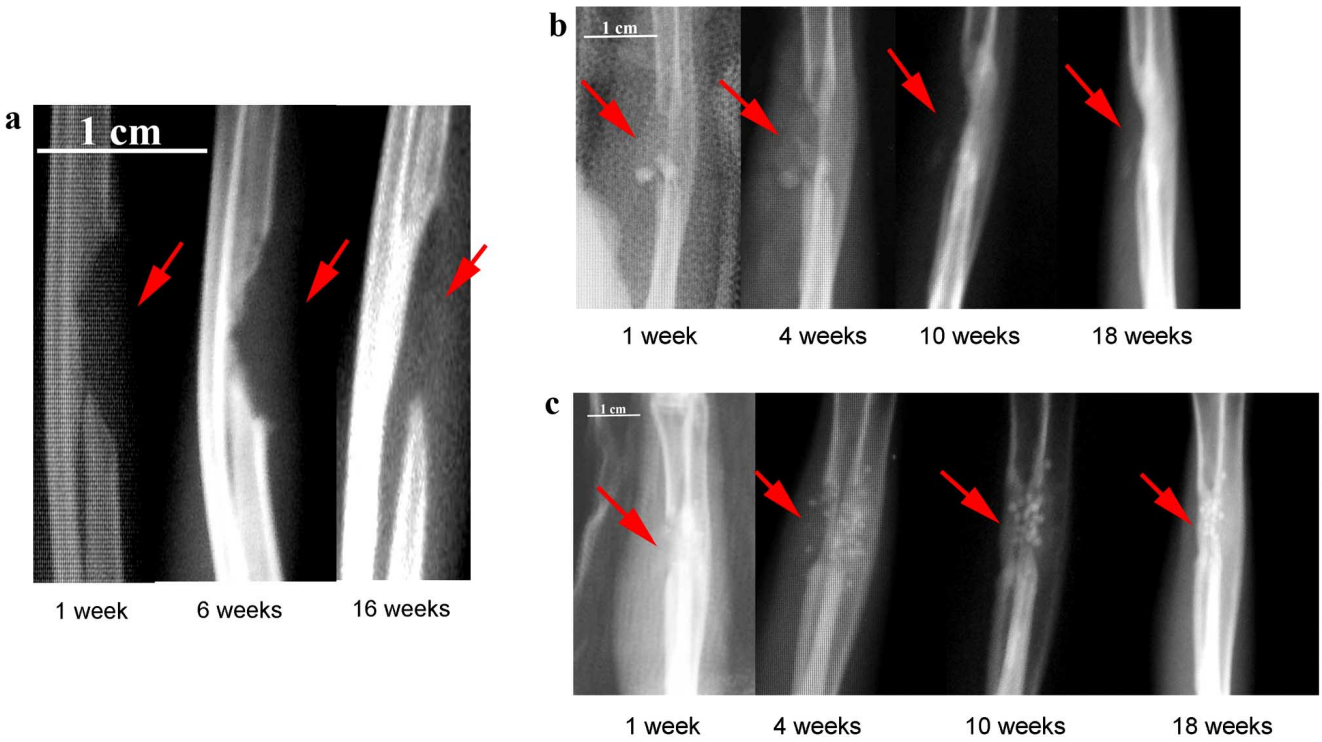

Fig. (4). Radiographs of some control and experimental rabbits. a. X-ray film of negative control (1,6 and 16 weeks after operation). The defect was not filled; b. and c. X-ray films of experimental rabbits (from 1 till 18 weeks after operation). The defect healing is shown. Arrows point to the sites of the defect.

blue (Merk, Germany) dissolved in $100 \mathrm{ml}$ distilled water, then added $2.0 \mathrm{~g}$ of orange $\mathrm{G}$ (Merk, Germany), then added $2.0 \mathrm{~g}$ of oxalic acid (Himmed, Russia), heated to boiling, filtered after cooling) for 2 minutes. Then the sections were washed in distilled water and differentiated in $96 \%$ ethanol until tints of blue appeared, dehydrated and mounted in Canada balsam.

\section{RESULTS}

Generally, the bone marrow aspirates contained (18.3 \pm 3.6) $\times 10^{6}$ nucleated cells. After 2 passages, usually ten T175 flasks with confluent monolayers of MMSCs were obtained. By this time, MMSCs had doubled more than 4 times (to passage $1-2.05 \pm 0.24$ doublings, and to passage $2-1.53 \pm$ 0.3 , calculated using formula (1)). On average, one T175 flask contained $(4.8 \pm 1.1) \times 10^{6} \mathrm{MMSCs}$ and after osteogenic induction, $-(4.6 \pm 1.2) \times 10^{6}$ cells. For characterisation of MMSCs in culture after 1 passage some of the MMSCs from each animal were induced to osteogeneic and adipogenic differentiation. After 2 weeks in induction media, cells were stained with appropriate dye and analysed. All samples differentiated successfully into these lineages. After 2 passages, MMSCs from one out of ten flasks were transduced by lentivector. The marking efficiency in transduced flask was analysed before implantation and was measured to be $38.3 \pm 5.7 \%$.

The X-ray analysis of bone regenerates was performed at $6,12,26$ and 52 weeks. None of control animals demonstrated bone defect healing (Fig. 4a). In animals treated with MMSCs the site of defect contained new bone tissue as early as 6 weeks after operation (Fig. 5a). Usually the bone defect started to fill in from the edges, and at 26 weeks after implantation virtually the entire region of defect was replaced with newly formed bone tissue (Fig. 5b). One year after implantation, the site of defect looked similar to intact bone (Fig. 5c). The resorption of calcium sulphate and calcium phosphate scaffolds was visualised by X-ray 10 weeks after operation (Fig. 4b,c). Autopsy revealed remains of ProDense cylinders as a soft white substance $1 \mathrm{~mm}$ in diameter, enclosed within a connective capsule outside the newly formed bone tissue.
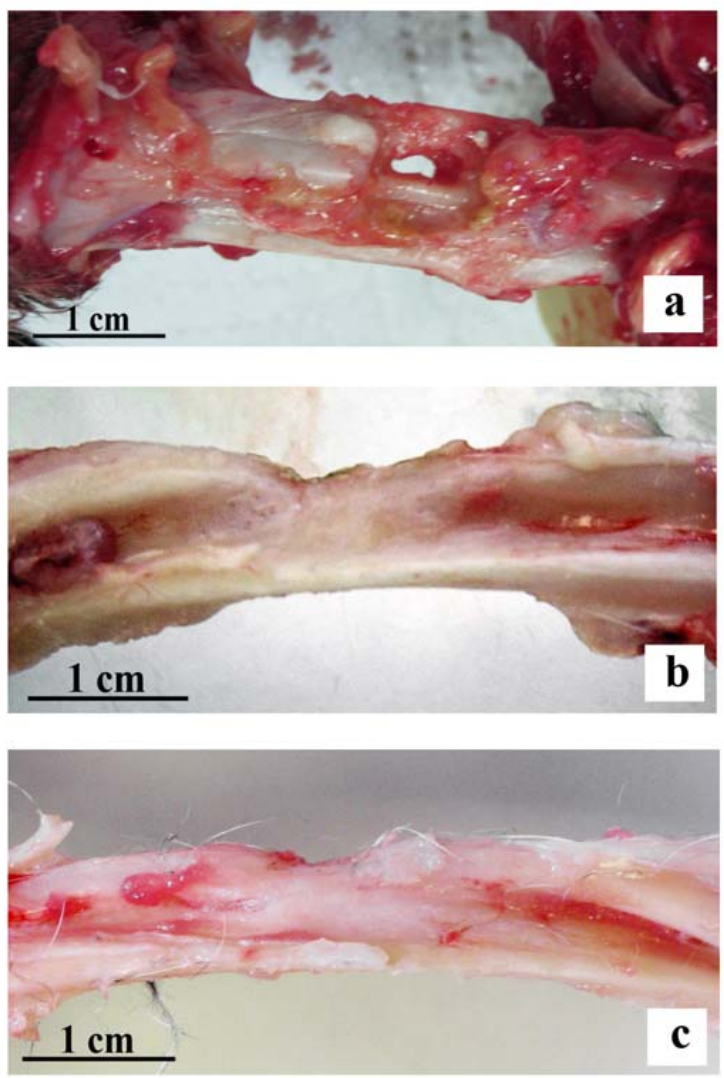

Fig. (5). The dynamics of healing the bone defect. a. 6 weeks after operation and MMSCs implantation; b. 26 weeks after operation and MMSCs implantation; c. 52 weeks after operation and MMSCs implantation. 
Table 1. Characteristics of Bone Tissue Regenerates after Implantation of Marked MMSC

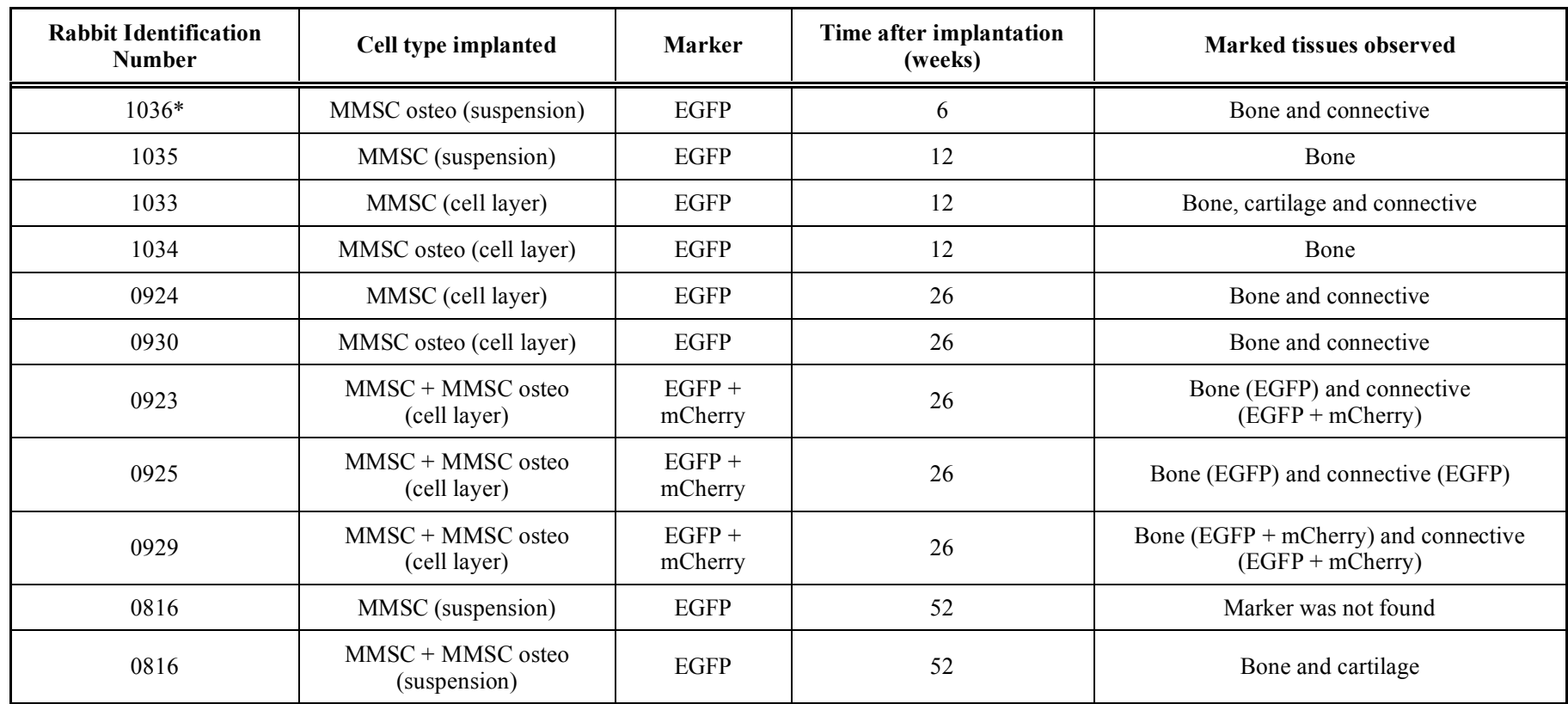

* This animal was sacrificed not according to the plan of the experiments due to force majeur.

The main features of MMSCs were studied by implantation of suspended MMSCs, as well as scraped fragments of monolayer. Preliminary dissociation of MMSCs did not lead to changes in their ability to regenerate bone (Table $\mathbf{1}$ ).

Induction of osteogenic differentiation for 4-6 days before implantation of MMSCs did not affect the rate and total longevity of defect healing (Table 1).

Throughout the duration of the experiment, marked cells were found in regenerated tissues. The transduced gene was observed in bone, cartilage and connective tissues of animals where MMSCs were implanted as well as in bone and connective tissues of animals where MMSCs that had been induced to undergo osteogeneic differentiation were implanted. Only one animal among 11 analysed for the presence of transduced genes did not contain the marker gene in regenerated bone tissue one year post-implantation (Table 1).

Areas of haematopoiesis were observed inside the mass of newly formed bone tissue (Fig. 6a,b). Sites of cartilage formation were also revealed in the regenerated tissue (Fig. 6c).

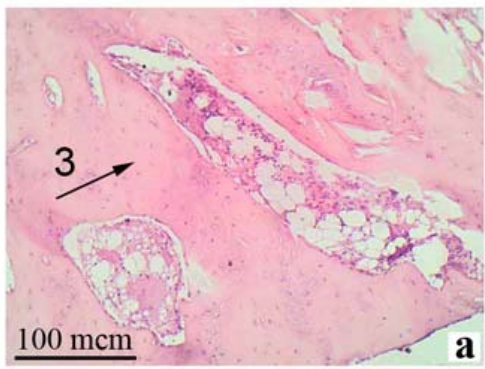

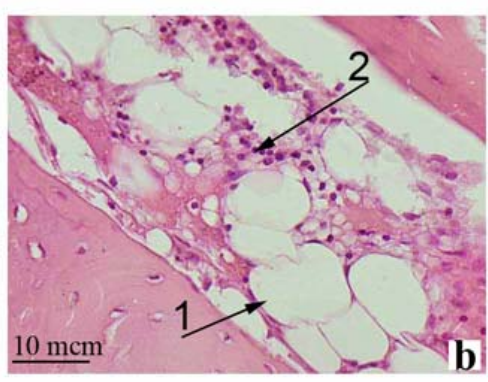

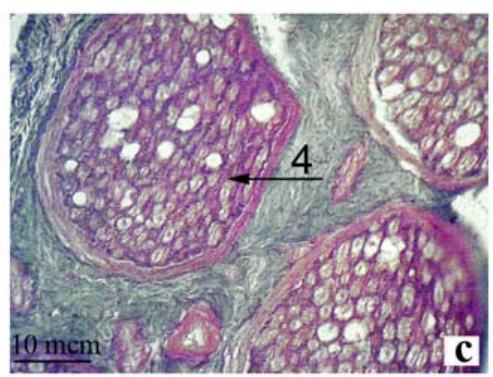

Fig. (6). Various tissue types within newly formed bone tissue 26 weeks after MMSCs implantation. a. Site of hematopoiesis with adipocytes in newly formed bone tissue, haematoxylin-eosin staining; $\mathbf{b}$. Site of hematopoiesis with adipocytes in newly formed bone tissue, haematoxylin-eosin staining; c. Cartilage formation, Mallory staining; Arrow 1 - adipocytes; Arrow 2 - hematopoietic cells; Arrow 3 - bone tissue; Arrow 4 - cartilage tissue. 


\section{DISCUSSION}

Implantation of MMSCs into never-healing bone defects lead to complete and stable regeneration of bone tissue. The calcium sulphate and calcium phosphate biomaterials used in the experiments temporarily functioned as replacement bone volume and as scaffolds for MMSCs. They were completely resorbed during first 10 weeks after implantation. Thus, the tissue filling the site of the defect was totally newly formed.

It was shown previously that murine MSCs lose their proliferative and differentiation potentials in the case of dissociation of bone marrow cells or adherent cell layers from long-term bone marrow cultures [19, 20]. Dissociation of rabbit MMSCs did not affect their ability to regenerate bone. This result could be explained by the fact that MMSCs were placed on macroporous sponge carrier (Indost) prior to implantation, which kept the cells in close proximity and thus enabled them to restore lost connections. Indeed, investigation of human MMSCs has revealed the ability of sorted cells to induce the formation of bone and haematopoietic stromal microenvironment when placed on a mineral scaffold and implanted into SCID mice [21]. Alternatively, the sensitivity of MMSCs to the loss of intercellular contacts could be species specific.

Preliminary short-term induction of osteogenic differentiation of MMSCs did not affect the outcome of their implantation. Obviously osteogenic differentiation was only induced but not completed before implantation as 4-6 days were not sufficient to complete terminal differentiation. Our aim was to transplant cells both capable of proliferation and differentiation and of participation in the regeneration of critical bone defect more rapidly. However such treatment of MMSCs did not lead to any improvement of defect healing, so this procedure is not necessary. It seems that mesenchymal stem cells responsible for tissue regeneration in vivo are not depend on the presence of induced to differentiation progeny at the site of damaged bone.

Marked cells took part into the regeneration and were detected in the regenerated region for 1 year. Taking into account that MMSCs were transduced with marker gene in only 1 out of 10 flasks used for transplantation and that the transduction efficiency was about $40 \%$, one could conclude that among implanted MMSCs, only 4\% contained the marker gene. Not more than $7 \%$ of marked human MMSCs with high proliferative potential in vitro were revealed among total population of MMSCs by Lee and co-authors [22]. In our experience, about $12.8 \%$ of marked cloned human MMSCs could reach confluent monolayer in the T25 flask, thus carrying through 15-17 doublings (unpublished data). After extrapolation of these data from human to rabbit MMSCs, it is possible to suggest that only $0.3 \%$ of MMSCs with high proliferative potential had been marked at the beginning. At that density, marked cells were revealed in all tissue regenerates. Therefore, some of the marked MMSCs possess high proliferative potential and ability to differentiate into bone, cartilage and connective tissues, as PCR analysis of DNA from the samples of these tissues revealed sequences of marker gene.

The tissue in the regenerated region is completely newly formed. Thus, haematopoietic microenvironment revealed in this region was also formed by implanted MMSCs. Cell components of haematopoietic microenvironment are the progeny of mesenchymal stem and precursor cells [23]. The appearance of the genes used as markers for cultivated MMSCs in all tissue types in regenerated tissue suggests that the bone and cartilage in tissue regenerates descended from autologous cultured marked MMSCs, but not from surrounding mesenchymal cells due to induction of osteogenesis by carriers and cells. Thus, the implanted MMSCs are polypotent in vivo.

Taken together, these data suggest that MMSCs display the main features of MSCs. In stem cell biology, unequivocal proof for in vivo self-renewal can be obtained only by transplanting the cells in vivo, waiting for tissue reconstitution, harvesting the engrafted cells again from the primary recipients, and transplanting them into secondary recipients. Self-renewal can only be confirmed if this process is successful. Using this method, the self-renewal ability of murine and human haematopoietic stem cells [24] as well as of murine mesenchymal stem cells [6] was demons-trated. For human MMSCs, it is possible to use this method only by forming the haematopoietic ectopic foci in SCID mice, what has not yet been done. However, long-term persistence of marked MMSCs in tissue regenerates supports the possibility that MMSCs with high proliferative potential and multipotency belong to the compartment of stem cells. Presence of true stem cells in the population of MMSCs provides the effective tool for healing persistent bone and cartilage defects.

These results emphasize the important role MMSCs could play in gene therapy and tissue engineering. The cells themselves and their progeny could be used for tissue regeneration and for stable and prolonged expression of the genetically modified gene of interest.

\section{CONCLUSIONS}

Here, we demonstrate that regeneration of large bone defects occurred by means of implanted MMSCs. The preservation of intracellular contacts was not necessary when using porous mineral carriers. Newly formed bone tissue appeared by 6 weeks after implantation of MMSCs and filled the entire region of defect by 26 weeks. Within a year after implantation, the site of the defect looked similar to intact radius bone. Preliminary induction of osteogenic differenttiation in vitro did not affect the dynamics of healing. Marking of MMSCs in vitro allowed the identification of cultured MMSCs that had differentiated into bone, cartilage and connective tissues in vivo. Implanted MMSCs took part in the maintenance of newly formed bone and cartilage tissues for at least a year, indicating their high proliferative potential.

The detection of marked cells in bone tissue one year after implantation of MMSCs suggests that these cells are a convenient tool for gene therapy. The similarity of growth characteristics of human and rabbit MMSCs permit extrapolation of these data to tissue engineering in humans as well.

The authors declare no potential conflicts of interest. 


\section{ACKNOWLEDGEMENTS}

The study was supported by Grant of Moscow Government agreement № 01/07-Hem-M from 01.01.2007. The materials maintained by Grants of Russian Fond of Fundamental Science 08-04-91952-ННИО а и 10-0400209-a were used.

The authors thank Gretsov E.A., Panteleev A.V. and Prof. Vorobiev I.A. (NRCH, Moscow, Russia) for assistance in estimating titre of lentiviruses by FACS analysis, Kristoffer Weber, Prof. Boris Fehse (University Hospital Eppendorf, Hamburg), Dr. Carol Stocking (Heinrich-PetteInstitute, Hamburg) and Roger Y. Tsien (Howard Hughes Medical Institute Laboratories at the University of California, San Diego) for providing the plasmids and cell line for lentivectors production, and Glasko E.N. (NRCH, Moscow, Russia) for analysis of histological slides.

\section{CONFLICT OF INTEREST}

None declared.

\section{REFERENCE}

[1] Dazzi F, Horwood NJ. Potential of mesenchymal stem cell therapy. Curr Opin Oncol 2007; 19: 650-5.

[2] Richardson SM, Hoyland JA, Mobasheri R, et al. Mesenchymal stem cells in regenerative medicine: opportunities and challenges for articular cartilage and intervertebral disc tissue engineering. $\mathbf{J}$ Cell Physiol 2010; 222: 23-32.

[3] Friedenstein AJ, Petrakova KV, Kurolesova AI, Frolova GP. Heterotopic of bone marrow.Analysis of precursor cells for osteogenic and hematopoietic tissues. Transplantation 1968; 6: 230-47.

[4] Caplan AI. Mesenchymal stem cells. J Orthop Res 1991; 9: 641-50.

[5] Friedenstein AJ, Piatetzky-Shapiro II, Petrakova KV. Osteogenesis in transplants of bone marrow cells. J Embryol Exp Morphol 1966; 16: 381-90.

[6] Chertkov JL, Gurevitch OA. Self-maintenance ability and kinetics of haemopoietic stroma precursors. Cell Tissue Kinet 1980; 13: $535-41$.

[7] Horwitz EM, Le Blanc K, Dominici M, et al. Clarification of the nomenclature for MSC: The International Society for Cellular Therapy position statement. Cytotherapy 2005; 7: 393-5.

[8] Chamberlain G, Fox J, Ashton B, Middleton J. Concise review: mesenchymal stem cells: their phenotype, differentiation capacity, immunological features, and potential for homing. Stem Cells 2007; 25: 2739-49.

[9] Dominici M, Paolucci P, Conte P, Horwitz EM. Heterogeneity of multipotent mesenchymal stromal cells: from stromal cells to stem cells and vice versa. Transplantation 2009; 87(9 Suppl): S36-S42.
[10] Wakitani S, Goto T, Pineda SJ, et al. Mesenchymal cell-based repair of large, full-thickness defects of articular cartilage. J Bone Joint Surg Am 1994; 76: 579-92.

[11] Wakitani S, Imoto K, Yamamoto $\mathrm{T}$, et al. Human autologous culture expanded bone marrow mesenchymal cell transplantation for repair of cartilage defects in osteoarthritic knees. Osteoarthritis Cartilage 2002; 10: 199-206.

[12] Krampera M, Pizzolo G, Aprili G, Franchini M. Mesenchymal stem cells for bone, cartilage, tendon and skeletal muscle repair. Bone 2006; 39: 678-83.

[13] Dounchis JS, Coutts RD, Amiel D. Cartilage repair with autogenic perichondrium cell/polylactic acid grafts: a two-year study in rabbits. J Orthop Res 2000; 18: 512-5.

[14] Nifontova IN, Svinareva DA, Drize NJ. Stromal clonogenic precursors of hemopoietic microenvironment and their rank in the hierarchy of mesenchymal stem cells. Bull Exp Biol Med 2008; 145: 544-7.

[15] Phinney DG, Kopen G, Isaacson RL, Prockop DJ. Plastic adherent stromal cells from the bone marrow of commonly used strains of inbred mice: variations in yield, growth and differentiation. J Cell Biochem 1999; 72: 570-85.

[16] Shao X, Goh JC, Hutmacher DW, Lee EH, Zigang G. Repair of large articular osteochondral defects using hybrid scaffolds and bone marrow-derived mesenchymal stem cells in a rabbit model. Tissue Eng 2006; 12: 1539-51.

[17] Giannoni P, Mastrogiacomo M, Alini M, et al. Regeneration of large bone defects in sheep using bone marrow stromal cells. J Tissue Eng Regen Med 2008; 2: 253-62.

[18] Todoerti K, Lisignoli G, Storti P, et al. Distinct transcriptional profiles characterize bone microenvironment mesenchymal cells rather than osteoblasts in relationship with multiple myeloma bone disease. Exp Hematol 2010; 38: 141-53.

[19] Chertkov JL, Drize NJ, Gurevitch OA. Hemopoietic stromal precursors in long-term culture of bone marrow: II. Significance of initial packing for creating a hemopoietic microenvironment and maintaining stromal precursors in the culture. Exp Hematol 1983; 11:243-8.

[20] Gurevich OA, Drize NI, Chertkov IL. [Importance of cell contacts for the differentiation of the precursor cells of hematopoietic stroma in long-term bone marrow cultures]. Biull Eksp Biol Med 1982; 94: 97-100.

[21] Sacchetti B, Funari A, Michienzi S, et al. Self-renewing osteoprogenitors in bone marrow sinusoids can organize a hematopoietic microenvironment. Cell 2007; 131: 324-36.

[22] Lee CC, Christensen JE, Yoder MC, Tarantal AF. Clonal analysis and hierarchy of human bone marrow mesenchymal stem and progenitor cells. Exp Hematol 2010; 38: 46-54.

[23] Chertkov JL, Drize NJ, Gurevich OA. Hemopoietic microenvironment and hemopoietic stroma precursors. Budapest Publishing house of the Hungarian Academy of Science, 1983; pp. 133-47.

[24] Chen BP, Galy A, Kyoizumi S, et al. Engraftment of human hematopoietic precursor cells with secondary transfer potential in SCID-hu mice. Blood 1994; 84: 2497-505. 